\title{
The Impact of Cloud Computing on Information Systems Agility
}

\author{
Mohamed S. Sawas \\ Faculty of Engineering and Info. Sciences \\ University of Wollongong in Dubai \\ s_sawas@hotmail.com
}

\section{Mohamed K. Watfa}

Faculty of Engineering and Info. Sciences

University of Wollongong in Dubai

MohamedWatfa @UOWdubai.ac.ae

\section{Abstract}

As businesses are encountering frequent harsh economic conditions, concepts such as outsourcing, agile and lean management, change management and cost reduction are constantly gaining more attention. This is because these concepts are all aimed at saving on budgets and facing unexpected changes. Latest technologies like cloud computing promise to turn IT, that has always been viewed as a cost centre, into a source of saving money and driving flexibility and agility to the business. The purpose of this paper is to first compile a set of attributes that govern the agility benefits added to information systems by cloud computing and then develop a survey-based instrument to measure these agility benefits. Our research analysis employs non-probability sampling based on a combination of convenience and judgment. This approach was used to obtain a representative sample of participants from potential companies belonging to various industries such as oil \& gas, banking, private, government and semi-governmental organizations. This research will enable decision makers to measure agility enhancements and hence compare the agility of Information Systems before and after deploying cloud computing.

Keywords: Cloud computing; Agility; Information Systems; Agile IS; Agile Business

\section{Introduction}

The notion of "doing more with less" had spread during thelast few decades as a result of tough economic conditions facing businesses. Examples of such conditions are: recurrent downturns and recessions. This difficult situation imposed fierce competition on companies, and obliged them to seek reduction of costs while at the same time maximize profit and customer value. Businesses have to turn into agile enterprises, i.e. to be able to sense changes in the environment and respond quickly to these changes (Overby et. al., 2006). The changes might happen at different levels: in the economy, in competitive environments or in customer needs, among others.

Agility is a characteristic of highly competitive organizations that can quickly make decisions in order to survive changes in uncertain, turbulent and complex environments. Agile organizations drive corporate benefits by focusing on short time to market, continuous improvement, customer value and fast response to market changes. The agility concept originated from the manufacturing field in the early nineties. It comprised two attributes: leanness and flexibility. Leanness is the elimination of non value-adding activities, whereas flexibility is the adaptability to changing market needs (Rimiené, 2011). Afterwards, agile methods were used in software development projects for complex systems that require frequent changes, quick response and short release times. Subsequently, agile methodology was applied to project management in general. Moreover, agile became a management philosophy, and the concept of agile enterprise emerged (Dove, 2001).

Research had shown that information system (IS) agility is one of the most vital factors in sustaining a firm's strategic alignment (J orfi et. al., 2011), therefore, it becomes clear that an agile enterprise necessitates an agile IS (Pessi et. al., 2009). IT departments face serious agility 
problems such as: outdated infrastructures, underutilized capacities, and rigid architectures. These problems hinder organizations' flexibility and responsiveness, increase costs and reduce efficiency.

\subsection{Problem Statement}

Cloud computing is a new model for fulfilling corporate IT needs. It is service based, flexible and cost effective. One of the important benefits of cloud computing (indicated by how much interest it received in the literature) is the agility it brings to a company's IS, and as a result, to the business itself.

Most of the research cites agility as one of the major attributes of cloud computing (Carroll et. al. , 2011) and it is believed that cloud computing improves IS agility. However, it is unclear how cloud computing, when integrated with existing components of an organization's IS, adds to the agility of that IS as a whole, and furthermore, how can we measure or estimate the claimed agility improvement. While the adoption of cloud computing among businesses is growing, cloud computing has not come of age yet, and apart from cloud vendors' marketing hype, little research effort has been conducted to determine the impact of cloud computing on IS agility (Yang, et. al. 2013) using various agility dimensions identified in former research work. Decision makers need to be able to realize the agility gains achieved by deploying cloud computing. Such ability will allow them to view the situation before and after the change, and thus, make an informed decision about adding cloud computing to their IT investment portfolios.

\subsection{Purpose of the Study \& Research Questions}

This study aims to build a framework for measuring agility changes, introduced by integrating cloud computing into the IS of a given organization. Also, it seeks to create a survey tool to measure those agility changes. The research question under study is: How to measure the impact of cloud computing on IS agility?

To answer that question, two sub-problems need to be addressed:

1. Determine the factors that affect agility of IS (attributes).

2. Design a survey-based instrument to measure agility changes, brought to the IS by cloud computing, based on the attributes determined in the first sub-problem.

\subsection{Research Methodology}

In order to validate the hypothesis claiming that cloud computing improves IS agility, a noncausal investigation is performed. It starts by conceptualizing the IS agility construct through a literature review, and then operationalizes the construct when cloud computing is deployed into the IS. Operationalization is done using a survey which is based on a compiled group of agility-related attributes. The study verifies any pre-existing correlation between different cloud computing service models and different categories of agility. Also, it makes and validates some claims in relation to the research question: To what extent, those who see agility improvement, exceed those who do not? The research is conducted in a non-contrived setting, using a survey on a longitudinal basis.

\subsection{Significance of the study}

Agility has been described as the capability to effectively sense and respond to environmental change. Much of the contemporary IS literature focuses on defining agility and on whether information systems enable agility in the enterprise. Also, due to the benefits that cloud computing offers businesses, many organizations have started building applications in the cloud, seeking enhanced business agility by using flexible and elastic cloud services. Nevertheless, moving applications and/or data into the cloud is not straightforward. To leverage the full potential promised by cloud computing, numerous challenges have to be addressed. These challenges are often related to the fact that existing applications have specific requirements. This research takes up the unaddressed question of whether cloud computing is 
really capable of enhancing IS agility, and how this enhancement materializes. Also, it enables decision makers to measure this agility enhancement and hence compare the agility of the IS before and after cloud computing is deployed.

\section{LITERATURE REVIEW}

\subsection{Information Systems Agility}

An information system is often considered as the heart of any organization; hence, the performance of the enterprise depends on the efficiency of its information system (Izza et al., 2008). The enterprise strategy is influenced by the socio economic, legislative and technology changes. Moreover, globalization of the economy makes enterprise information systems more complex and makes competition increasingly fierce. Therefore, to ensure survival and sustainability of the enterprise, it must be permanently agile. Enterprise policies must rapidly adapt to the enterprise strategy, in other words, an enterprise must quickly drive important changes at all levels and dimensions, in order to align them to its strategy and vice versa. This can be achieved by relying on an appropriate set of best practices and/ or standards. Actually, the information system is becoming a tool of strategy for most organizations. Earlier research on measuring agility of information systems surveyed different levels of IT staff, using questionnaires, to assess various dimensions of agility in an IS. Maurer (Maurer, 2010) provides a definition of IS agility by combining many agility aspects from prior research. He defines IS agility based on three second-order dimensions (technical infrastructure agility, IS process agility and human characteristics); each one of them is broken down into 3-4 firstorder dimensions. Then he provides an overview of a reliable survey-based scale that measures IS agility. Imache, Izza and Nacer (2012) propose a POIRE framework composed of five elements (Process, Organization, Information, Resource and Environment) to assess enterprise IS agility based on two main principles: urbanization and continuous improvement. They employ a survey instrument that consists of a group of criteria (questions) and a fuzzy logic method to perform evaluation for these five dimensions. Terry and Douglas (Byrd et al., 2000) define the IT infrastructure flexibility construct, operationalize it by developing a survey-based measurement instrument, which is created based on some predefined dimensions of IT infrastructure flexibility, and then employ statistical processes to validateand verify reliability of the measurement.

\subsection{Cloud Computing}

Cloud computing has emerged as a paradigm to deliver on demand resources (e.g., infrastructure, platform, software, etc.) to customers similar to other utilities (e.g., water, electricity and gas). Three main services are provided by a cloud computing architecture according to the needs of IT customers (Buyya et. al., 2009). Firstly, Software as a Service (SaaS) provides access to complete applications as a service, such as Customer Relationship Management (CRM) (Cusumano, 2010). Secondly, Platform as a Service (PaaS) provides a platform for developing other applications on top of it, such as the Google App Engine (GAE) (Ciurana, 2009). Finally, Infrastructure as a Service (IaaS) provides an environment for deploying, running and managing virtual machines and storage. Technically, IaaS offers incremental scalability (scale up and down) of computing resources and on-demand storage (Buyya et. al., 2009).

Carroll, van der Merwe \& Kotze (2011) studied existing research on cloud computing, and conducted interviews with 15 senior managers in order to outline cloud computing benefits and security risks, and then recommended some controls to mitigate these risks. Finally, they suggested creating a comprehensive framework of risk and control for cloud computing. The 'Cloud Services Measurement Initiative Consortium' CSMIC developed a hierarchical framework that contains a number of key performance indicators (KPIs) or metrics to measure and compare different cloud services (Perdue et. al., 2011). Garg, Versteeg \& Buyya (2013), proposed a framework to quantitatively measure IaaS cloud services based on the Service Measurement Index (SMI) metrics suggested by Cloud Service Measurement Index Consortium (CSMIC). They developed a mechanism to discover, monitor, and calculate service 
metrics for different cloud providers, and then rank them and select the best one meeting user's essential and non-essential requirements. Different metrics are weighted according to user's priorities and the Analytical Hierarchy Process (AHP) method is used to rank cloud services. Finally, they applied the AHP calculation method in an example case to obtain the metrics for three cloud service providers and rank them accordingly. Li, O'Brien, Zhang \& Cai (2013), aiming for evaluating and benchmarking commercial cloud services, compiled a catalog of de facto metrics using a systematic literature review (SLR) of existing cloud services evaluation work. Yang, Huff \& Tate (2013) worked on the conceptualization of IS agility based on prior research to evaluate the contribution of different cloud computing services to the IS agility.

Cloud computing promises everything, from reduced complexity and unlimited scalability to capacity on demand and CapEx savings. Although there are still many unanswered questions about cloud computing, many businesses are optimistic that it will be able to deliver on these promises. Even skeptics are intrigued by cloud computing, if for no other reason than that they want to maintain a technological edge over their competitors, and the cloud is certainly the new technology trend. To whatever extent cloud computing delivers on these promises, one thing is certain: businesses are not willing to sacrifice security, visibility, and control to make the move to the cloud. They need to know what is happening in the cloud, how their applications are being delivered, and how traffic is being controlled and directed. What is emerging as a "must have" in cloud computing is agility: the quality that enables enterprises to respond quickly and precisely to unexpected and changing business demands. Agile businesses, those that can provide IT on demand under any workload conditions, can seizenew opportunities and stay competitive. This is what led us to further pursue this research to see whether or not cloud computing is really capable of enhancing IS agility and how much would companies be willing to sacrifice other cloud computing offerings.

Table 1 summarizes our literature review, highlighting the different methodologies and contributions. Figure 1 presents a bibliographical tree of relevant prior research, detailing how various research work relates to or elaborates on each other and the gap in the research literature. 


\begin{tabular}{|c|c|c|c|c|}
\hline Ref. & $\begin{array}{l}\text { Research } \\
\text { Question }\end{array}$ & Methodology & Theoretical basis & Conclusion/extension \\
\hline $\begin{array}{l}\text { (Maurer, } \\
2010) .\end{array}$ & $\begin{array}{l}\text { Combine earlier } \\
\text { definitions of IS } \\
\text { agility and outline } \\
\text { steps for developing } \\
\text { a reliable scale to } \\
\text { measure it }\end{array}$ & $\begin{array}{l}\text { Conceptual; } \\
\text { Synthesis of } \\
\text { previous research } \\
\text { works }\end{array}$ & $\begin{array}{l}\text { Prior research focused on } \\
\text { three main aspects of IS } \\
\text { agility: agility of the IT } \\
\text { technical infrastructure, } \\
\text { the supporting processes, } \\
\text { and the staff }\end{array}$ & $\begin{array}{l}\text { Gives a brief overview of a } \\
\text { measurement scale, the } \\
\text { validation and finalization of it } \\
\text { yet to be performed }\end{array}$ \\
\hline $\begin{array}{l}\text { (Imache } \\
\text { et. al., } \\
\text { 2012) }\end{array}$ & $\begin{array}{l}\text { Apply the POIRE } \\
\text { framework to IS } \\
\text { agility and measure } \\
\text { it using fuzzy logic }\end{array}$ & Survey and case & $\begin{array}{l}\text { Agility is assessed using } \\
\text { fuzzy logic based on four } \\
\text { dimensions: production } \\
\text { infrastructure, market } \\
\text { infrastructure, people } \\
\text { infrastructure and } \\
\text { information infrastructure }\end{array}$ & $\begin{array}{l}\text { Applying the model to estimate } \\
\text { the agility of a sample company } \\
\text { clarified the connection and the } \\
\text { consistency among the different } \\
\text { components of the POIRE } \\
\text { framework and its practicability. } \\
\text { The model ignores the } \\
\text { interactions between the } \\
\text { dimensions, factors and criteria }\end{array}$ \\
\hline $\begin{array}{l}\text { (Byrd et } \\
\text { al., 2000) }\end{array}$ & $\begin{array}{l}\text { Define the flexibility } \\
\text { construct, develop a } \\
\text { measurement } \\
\text { instrument, } \\
\text { statistically analyze, } \\
\text { validate and verify its } \\
\text { reliability }\end{array}$ & $\begin{array}{l}\text { Conceptual and } \\
\text { Survey }\end{array}$ & $\begin{array}{l}\text { IT infrastructure flexibility } \\
\text { construct }\end{array}$ & $\begin{array}{l}\text { Further refinement of } \\
\text { discovered factors, the relative } \\
\text { contribution of each factor to the } \\
\text { competitive advantage, relation } \\
\text { between flexibility, its costs and } \\
\text { its benefits }\end{array}$ \\
\hline $\begin{array}{l}\text { (Carroll et. } \\
\text { al, 2011) }\end{array}$ & $\begin{array}{l}\text { Outline cloud } \\
\text { computing benefits } \\
\text { and security risks } \\
\text { and then recommend } \\
\text { some controls to } \\
\text { mitigate those risks }\end{array}$ & $\begin{array}{l}\text { Qualitative } \\
\text { approach, interview } \\
15 \text { senior managers. }\end{array}$ & $\begin{array}{l}\text { Prior research on cloud } \\
\text { computing benefits and } \\
\text { risks }\end{array}$ & $\begin{array}{l}\text { Suggests creation of a } \\
\text { comprehensive framework of } \\
\text { risk and control for cloud } \\
\text { computing }\end{array}$ \\
\hline $\begin{array}{l}\text { (Garg et. } \\
\text { al. , 2013) }\end{array}$ & $\begin{array}{l}\text { Propose a framework } \\
\text { to evaluate cloud } \\
\text { offerings and rank } \\
\text { them based on their } \\
\text { ability to meet the } \\
\text { user's Quality of } \\
\text { Service (QoS) } \\
\text { requirements }\end{array}$ & $\begin{array}{l}\text { Designing metrics } \\
\text { for each } \\
\text { quantifiable QoS } \\
\text { attribute for } \\
\text { measuring the } \\
\text { service level of } \\
\text { cloud providers }\end{array}$ & $\begin{array}{l}\text { Attributes of services from } \\
\text { Service Measurement } \\
\text { Index (SMI) metrics by } \\
\text { Cloud Service } \\
\text { Measurement Index } \\
\text { Consortium (CSMIC) and } \\
\text { Service ranking using } \\
\text { Analytical Hierarchy } \\
\text { Process (AHP) }\end{array}$ & $\begin{array}{l}\text { Extend the ranking algorithm to } \\
\text { adapt variations in QoS } \\
\text { attributes using fuzzy sets, } \\
\text { extend the quality model to non- } \\
\text { quantifiable QoS attributes, } \\
\text { apply the SMI framework on } \\
\text { infrastructures provided by } 2 \\
\text { cloud vendors, extend a cloud } \\
\text { application platform to utilize } \\
\text { services of the framework }\end{array}$ \\
\hline $\begin{array}{l}\text { (Li, et. al. } \\
\text { 2013) }\end{array}$ & $\begin{array}{l}\text { Identify, assess and } \\
\text { synthesize the } \\
\text { published primary } \\
\text { studies of cloud } \\
\text { services evaluation }\end{array}$ & $\begin{array}{l}\text { Systematic } \\
\text { Literature Review }\end{array}$ & $\begin{array}{l}\text { Existing cloud services } \\
\text { evaluation work }\end{array}$ & $\begin{array}{l}\text { Evaluate elasticity andsecurity of } \\
\text { commercial cloud services, } \\
\text { develop more sophisticated } \\
\text { metrics for better evaluation }\end{array}$ \\
\hline $\begin{array}{l}\text { (Yang, et. } \\
\text { al. 2013) }\end{array}$ & $\begin{array}{l}\text { Conceptualize IS } \\
\text { agility and how cloud } \\
\text { computing might } \\
\text { facilitate it }\end{array}$ & $\begin{array}{l}\text { Cloud computing } \\
\text { services are } \\
\text { evaluated based on } \\
\text { different } \\
\text { dimensions of IS } \\
\text { agility }\end{array}$ & $\begin{array}{l}\text { Prior research on cloud } \\
\text { computing services }\end{array}$ & $\begin{array}{l}\text { IaaS has the potential to deliver } \\
\text { agility whereas PaaS, and SaaS } \\
\text { agility gains depend on } \\
\text { organizational and human } \\
\text { factors }\end{array}$ \\
\hline
\end{tabular}

Table 1. Summary of relevant literature including methodology used and corresponding theoretical basis. 


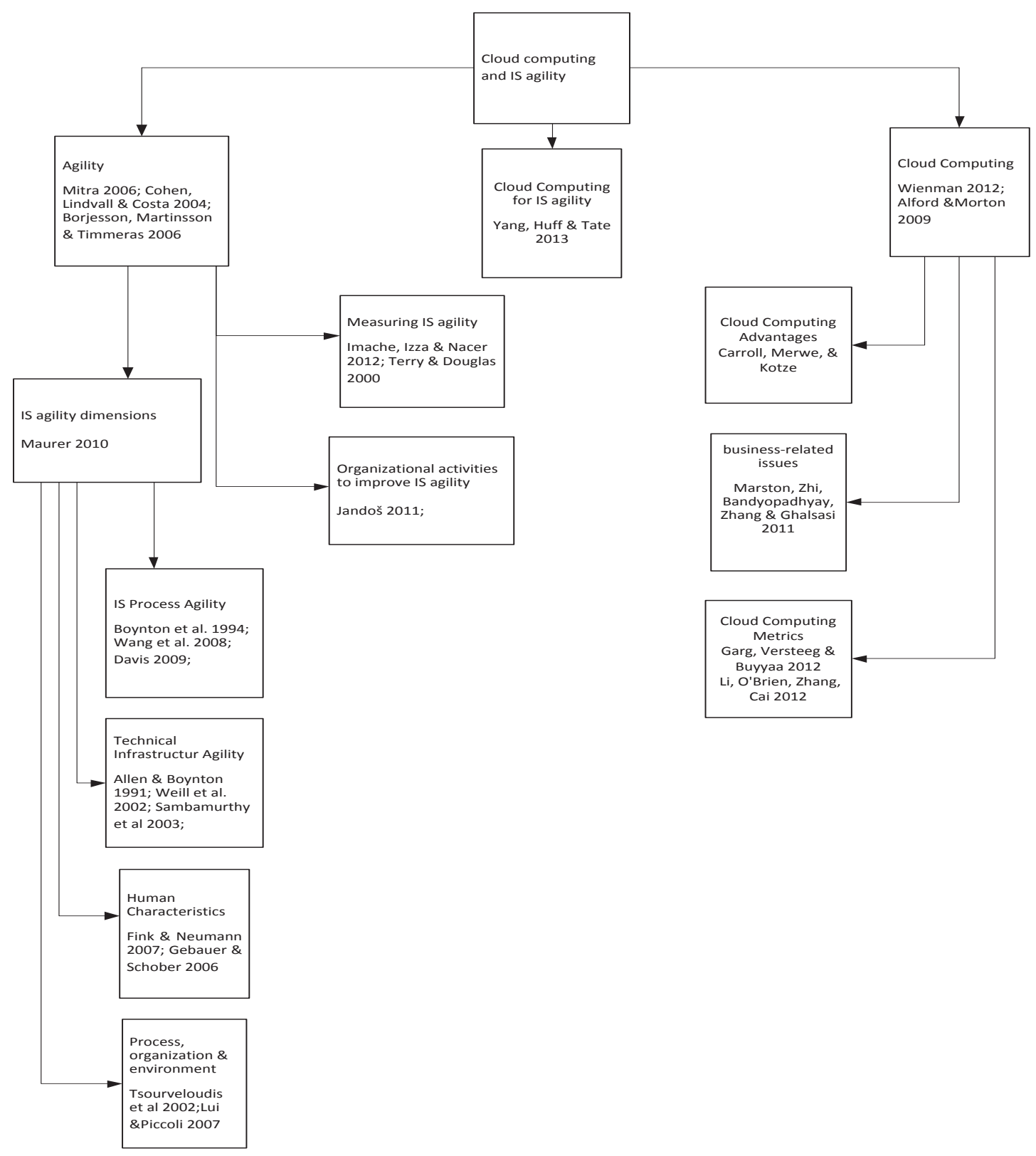

Figure 1. Bibliography Tree summarizing the gap in the literature. Arrows indicate further research conducted on specific aspects.

\section{DATA COLLECTION AND ANALYSIS}

\subsection{Sampling}

The unit of analysis is an organization that already has some kind of cloud computing as part of its IS. Sampling details regarding are listed below:

- $\quad$ Target Population: data were collected from IT managers, CIOs, CTOs, and senior IT professionals from selected UAE organizations that use any form of cloud computing.

- $\quad$ Sampling Method: non-probability sampling, based on a combination of convenience and judgment to obtain a representative sample. 
- $\quad$ Selection Procedure: select participants from potential companies belonging to various industries, such as oil \& gas, banking, private, government and semigovernmental organizations.

- $\quad$ Sample Size: 78 companies.

\subsection{Operationalization}

The suggested framework to measure the different agility aspects is shown in Figure 2. Survey questions are related to different agility categories and subcategories mapped to our proposed framework of attributes. The result is a set of twenty eight different questions as summarized in Table 2. Table 3 is a matrix that maps attributes in the framework above to different types of survey questions.

\section{General information}

1. Demographic Information

2. Our organization uses the following cloud service models

3. Our organization uses the following cloud deployment models

\section{Technical Infrastructure Agility}

Application Agility

4. Our organization is adding new products/services, with our cloud deployment in place, less time and effort is needed to add or modify the applications necessary to support those new products/ services

5. In my opinion, using cloud computing enhanced our ability to create reusable applications

Information Agility

6. If I need to share some data from one of our cloud applications with somebody outside the organization, I would be able to export that data using standard formats (such as xml)

7. I believe that deploying cloud applications improved information sharing within our organization and between our organization and external partners

8. If an employee wants to retrieve data from an application, he would experience faster access if the application resides in the cloud rather than on-premises

Compatibility \&interoperability

9. If a need arises to migrate our cloud applications from one cloud service provider to another, I would see a smooth and easy migration process

10. A business requirement dictates connecting our on-premises environment to our cloud environment by linking a cloud application with an on-premises application, I believe it is possible to achieve that requirement easily and securely

Elasticity

11. When a customer-facing cloud application witnesses an increasing demand from our customers (because of seasonal or unexpected reasons), it can increase its resource consumption on the fly to meet that demand and then reverts to normal level when demand falls

12. Our business is expanding and I want our cloud applications to cope with that expansion, all I need to do is to contact our cloud service provider and inform it about the required increase in allocated bandwidth and computing resources

\section{IT Processes Agility}

Maintenance Process Agility

13. In my opinion, compared to traditional applications, cloud applications require less time and effort for support and maintenance

14. A new branch of our business will be opened, I can tell that Integrating the new branch into our enterprise has become less complex since we used the cloud 


\begin{abstract}
Planning Process Agility
15. Now that our IT infrastructure contains both cloud and on-premises components, when I have to evaluate and prioritize proposed changes, I find it easier than before

16. Since we started deploying systems and applications in the cloud and because of cloud elasticity features, I feel more relieved from complicated capacity planning

Monitoring and Assessment Process Agility

17. Compared to traditional IT systems, gathering performance information for systems in the cloud seems easier

18. Upon introducing cloud systems into our environment, I noticed that service management became less complex than before
\end{abstract}

\title{
Human Characteristics
}

Training \& Staff

19. A new IT staff member was hired and she is learning to work with different systems and applications managed by our department, it is obvious that the training required for cloud systems is less (compared to traditional IT systems)

20. Migrating some of our systems to the cloud reduced the number of IT staff required to manage those systems

Business and Technical Skills

21. I think, as a result of utilizing the cloud, IT staff's task in translating business problems into technical solutions became simpler

22. I think that compared to traditional IT systems, cloud systems are less prone to human error

23. Utilizing cloud computing in our business did not require IT staff to learn new IT service delivery skills

\section{Business Aspects}

Response

24. Utilizing cloud computing made me feel more confident in our ability to counter unexpected changes (i.e. unexpected events such as corrections and reconfigurations)

25. After we added cloud technologies to our IT investment portfolio, I feel more satisfied about our efficiency and effectiveness in seizing emerging opportunities

Customer service

26. After moving a customer-facing application to the cloud, our customers' feedback indicates a notable improvement in customer service

Competitive status

27. From my experience with our business, I see a positive contribution of using the cloud to the alignment of IT strategies with business strategies

28. Cloud computing helped our organization to widen the array of products and/or services offered without increasing cost.

Table 2. Interview questions using our proposed framework. 


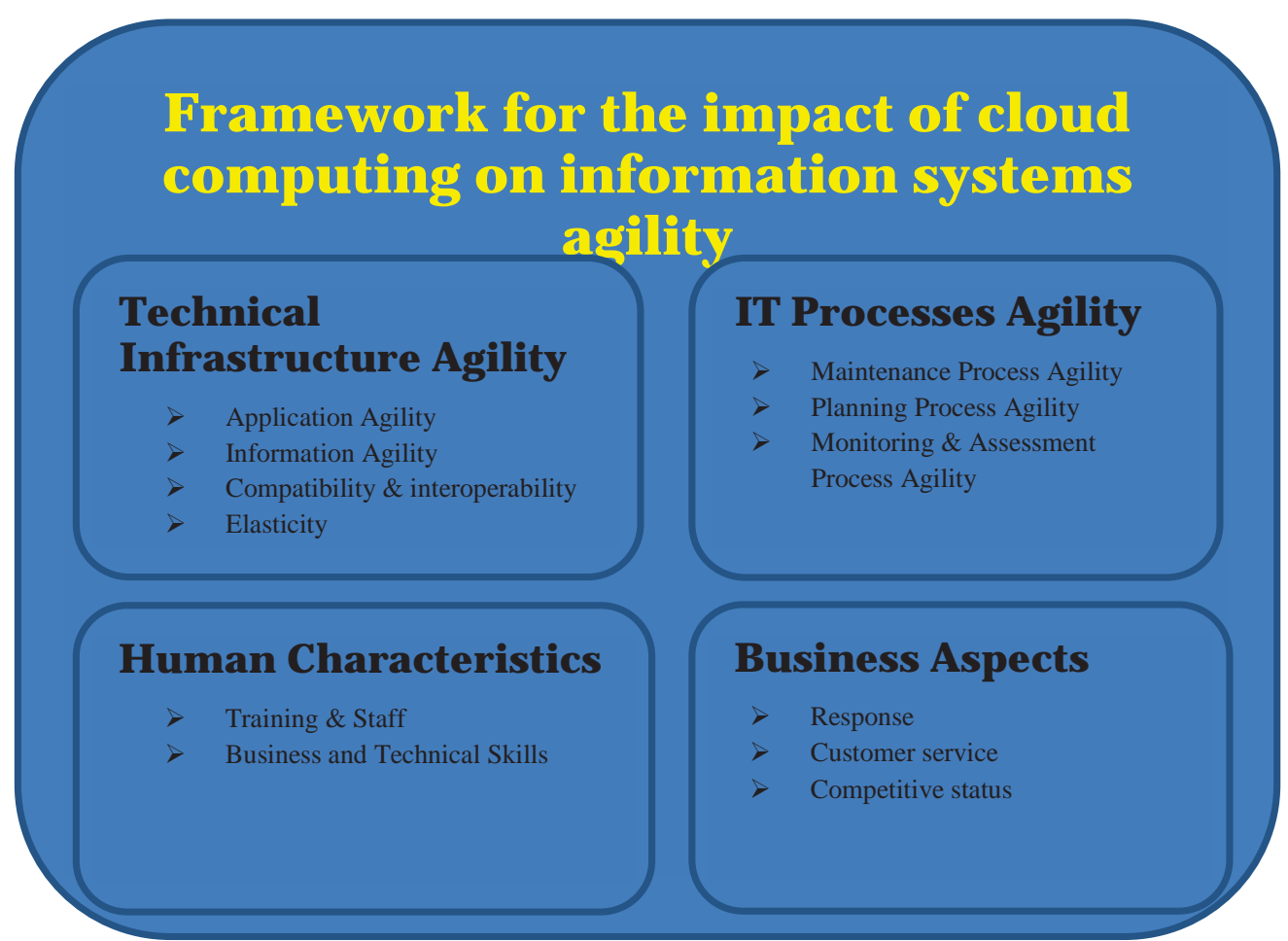

Figure 2. Framework for the impact of cloud computing on information systems agility

\begin{tabular}{|c|c|c|c|c|c|c|c|c|}
\hline \multirow[t]{2}{*}{$\begin{array}{l}\text { Attribute } \\
\text { Category }\end{array}$} & \multicolumn{2}{|c|}{ Attribute Name } & \multirow[t]{2}{*}{$\begin{array}{l}\text { Behav- } \\
\text { iour }\end{array}$} & \multirow[t]{2}{*}{$\begin{array}{l}\text { Opin- } \\
\text { ion }\end{array}$} & \multirow[t]{2}{*}{$\begin{array}{l}\text { Feel- } \\
\text { ing }\end{array}$} & \multirow{2}{*}{$\begin{array}{l}\begin{array}{l}\text { Know- } \\
\text { ledge }\end{array} \\
\text { Q 2,3 }\end{array}$} & \multirow[t]{2}{*}{ Sensory } & \multirow{2}{*}{$\begin{array}{l}\begin{array}{l}\text { Demo- } \\
\text { graphic }\end{array} \\
\text { Q } 1\end{array}$} \\
\hline & 0 & General information & & & & & & \\
\hline \multirow{4}{*}{$\begin{array}{l}\text { Technical } \\
\text { Infrastructure } \\
\text { Agility }\end{array}$} & 1 & Application Agility & & Q 5 & & & Q 4 & \\
\hline & 2 & Information Agility & Q 6 & Q 7 & & & Q 8 & \\
\hline & 3 & $\begin{array}{l}\text { Compatibility \& } \\
\text { interoperability }\end{array}$ & & Q 10 & & & Q 9 & \\
\hline & 4 & Elasticity & Q 12 & & & & Q 11 & \\
\hline \multirow[t]{3}{*}{$\begin{array}{l}\text { IT Processes } \\
\text { Agility }\end{array}$} & 5 & $\begin{array}{l}\text { Maintenance Process } \\
\text { Agility }\end{array}$ & & Q 13 & & & Q 14 & \\
\hline & 6 & $\begin{array}{l}\text { Planning Process } \\
\text { Agility }\end{array}$ & & & Q 16 & & Q 15 & \\
\hline & 7 & $\begin{array}{l}\text { Monitoring \& } \\
\text { Assessment Process } \\
\text { Agility }\end{array}$ & & & & & Q 17,18 & \\
\hline \multirow{2}{*}{$\begin{array}{l}\text { Human } \\
\text { Characteristics }\end{array}$} & 8 & Training \& Staff & & & & Q 20 & Q 19 & \\
\hline & 9 & $\begin{array}{l}\text { Business and } \\
\text { Technical Skills }\end{array}$ & & Q 21,22 & & Q 23 & & \\
\hline \multirow{3}{*}{$\begin{array}{l}\text { Business } \\
\text { Aspects }\end{array}$} & 10 & Response & & & Q 24,25 & & & \\
\hline & 11 & Customer service & & & & & Q 26 & \\
\hline & 12 & Competitive status & & & & Q 28 & Q 27 & \\
\hline
\end{tabular}

Table 3. Attribute- Question Type Matrix

\subsection{Data Collection}

We created an internet survey using an online survey tool. This tool sends email invitations with a link to the survey to all participants. It allows the user to collect data and export it as a standard text file for further analysis. 


\subsection{Data Analysis}

Data from the online survey tool were imported into IBM SPSS Statistics software version 21 to perform cross tabulation, Chi-Square, and single population t-tests. Detailed frequency tables of responses to the aggregated IS agility categories are summarized as bar charts in the results section below. Cross-tabulations of aggregated IS agility categories and service models along with their Chi-Square tests were performed to find any associations between the cloud service model used and the different categories of IS agility. Also, different single population t-tests were performed to test several hypotheses related to the average number of population elements who see agility improvement in its different models.

More specifically, the following sixteen hypotheses were formulated and tested at 95\% confidence level. The first twelve hypotheses (H1-H12) include different association existence between the different agility categories and cloud computing models formulated as follows:

H1-H12: There is no association between using a software model as a cloud service model and improving the IS Agility category of the IS where the cloud model is either IIaaS, PaaS, or SaaS\} \& the IS agility category is either \{Technical Infrastructure Agility (TIA), IT Processes Agility (IPA), Human Characteristics (HC), or Business Aspects (BA) \}

The next four hypotheses (H13-H16) include different association existence between the different agility categories and cloud computing models formulated as follows:

H13-H16: The average number of population elements who see agility improvement in an agility category exceeds the number of those who see otherwise by less than $\mathrm{X} \%$ where the IS agility category is either \{Technical Infrastructure Agility (TIA), IT Processes Agility (IPA), Human Characteristics (HC), or Business Aspects (BA) \} and X is to be determined accordingly.

\section{RESULTS}

This section summarizes the final results. Tables 4 and 5 depict usage frequencies and percentages for various cloud computing service models and deployment models. Figure 3. shows responses to the aggregated IS agility categories.

\begin{tabular}{|cc|c|c|}
\cline { 3 - 4 } \multicolumn{1}{c|}{} & Responses \% & Percent of Cases \\
\hline \multirow{2}{*}{ Service } & IaaS & $52.4 \%$ & $78.6 \%$ \\
Model $^{\mathrm{a}}$ & PaaS & $19.0 \%$ & $28.6 \%$ \\
& SaaS & $28.6 \%$ & $42.9 \%$ \\
& Total & $100.0 \%$ & $150.0 \%$ \\
\hline
\end{tabular}

a. Dichotomy group tabulated at value 1.

Table 4. Cloud computing service models usage frequencies and percentages

\begin{tabular}{|c|c|c|c|}
\hline & & Responses \% & Percent of Cases \\
\hline \multirow{4}{*}{$\begin{array}{c}\text { Deployment } \\
\text { Model }^{\mathrm{a}}\end{array}$} & $\begin{array}{l}\text { Public } \\
\text { Cloud }\end{array}$ & $26.1 \%$ & $33.3 \%$ \\
\hline & $\begin{array}{c}\text { Hybrid } \\
\text { Cloud }\end{array}$ & $13.0 \%$ & $16.7 \%$ \\
\hline & $\begin{array}{l}\text { Private } \\
\text { Cloud }\end{array}$ & $60.9 \%$ & $77.8 \%$ \\
\hline & Total & $100.0 \%$ & $127.8 \%$ \\
\hline
\end{tabular}

a. Dichotomy group tabulated at value 1.

Table 5. Cloud computing deployment models usage frequencies and percentages 


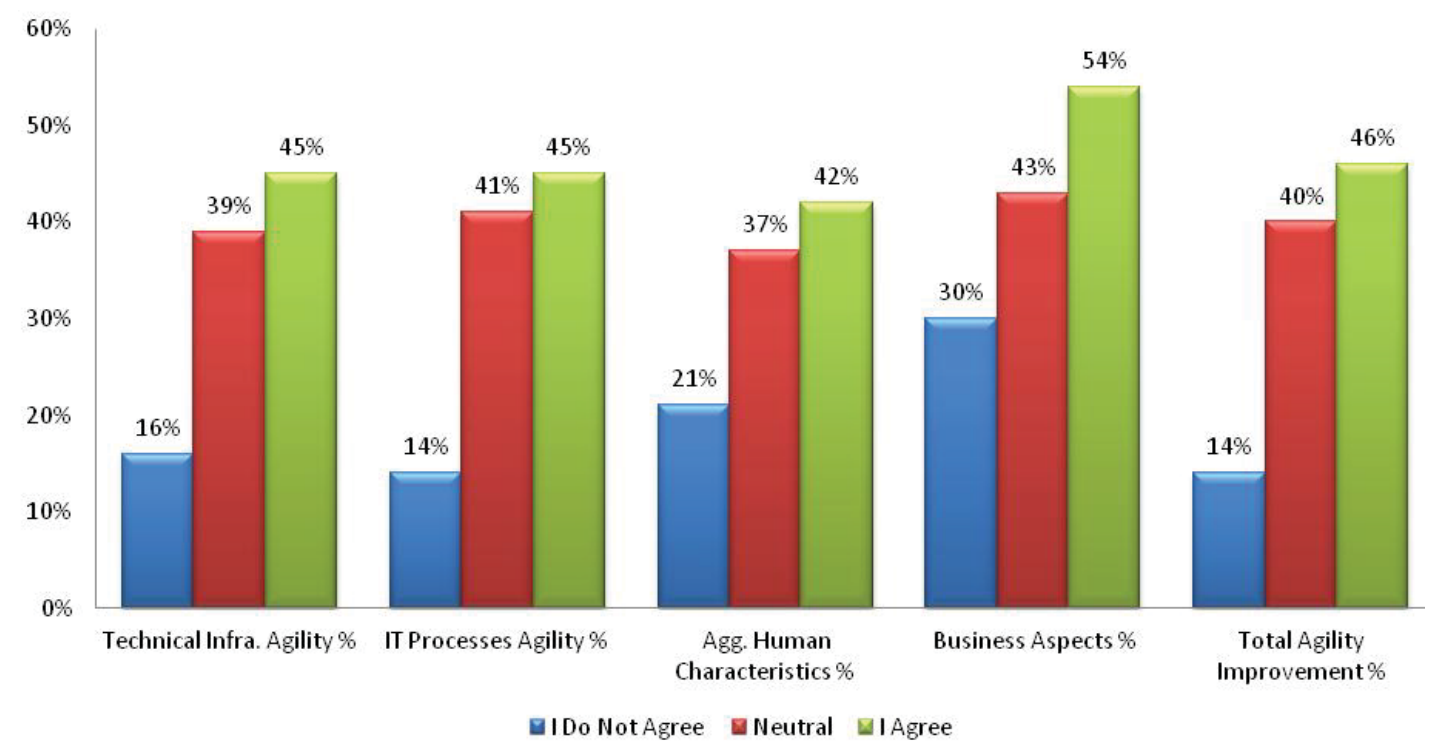

Figure 3. Combined Frequency distributions for responses to the aggregated IS agility categories from a total of 162 respondents.

As can be seen in Table 4 and Table 5, the Infrastructure-as-a-Service as well as the private cloud dominate the usage percentages which is quite expected when it comes to the IT infrastructure in the UAE. Also, an interesting observation from Figure 3, includes the high percentage of responses to the business aspects agility category including: more user confidence to counter unexpected changes (i.e. unexpected events such as corrections and reconfigurations), more satisfaction about the efficiency and effectiveness in seizing emerging opportunities, and a positive contribution of using the cloud to the alignment of IT strategies with business strategies.

For analysing the associations between the cloud service models used and the categories of IS agility, Figure 4 summarizes the cross tabulation results between the different agility categories and cloud models responses.

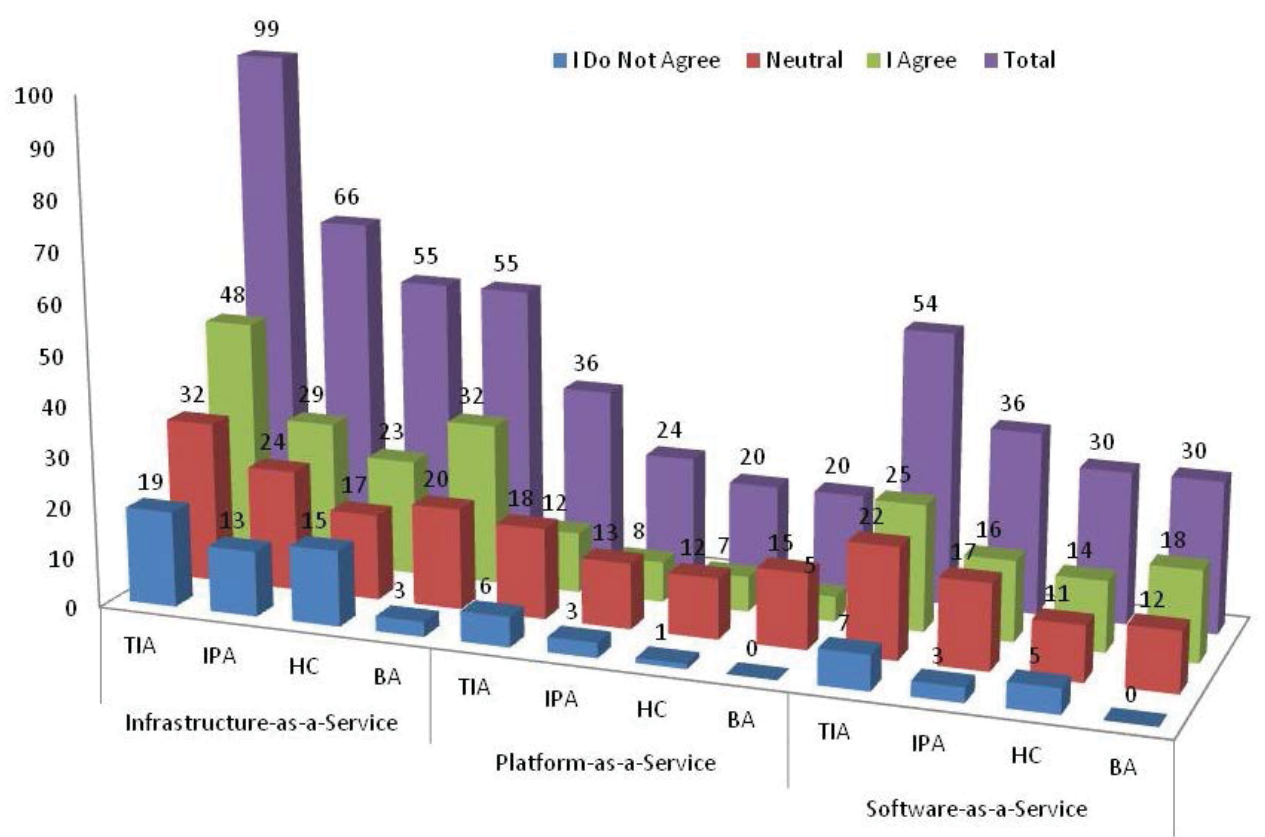

Figure 4. Technical Infrastructure Agility (TIA), IT Processes Agility (IPA), Human Characteristics (HC), Business Aspects (BA) Service Model Cross tabulation results. 
For testing the first twelve hypotheses (H1-H12), Table 6 summarizes the results from SPSS.

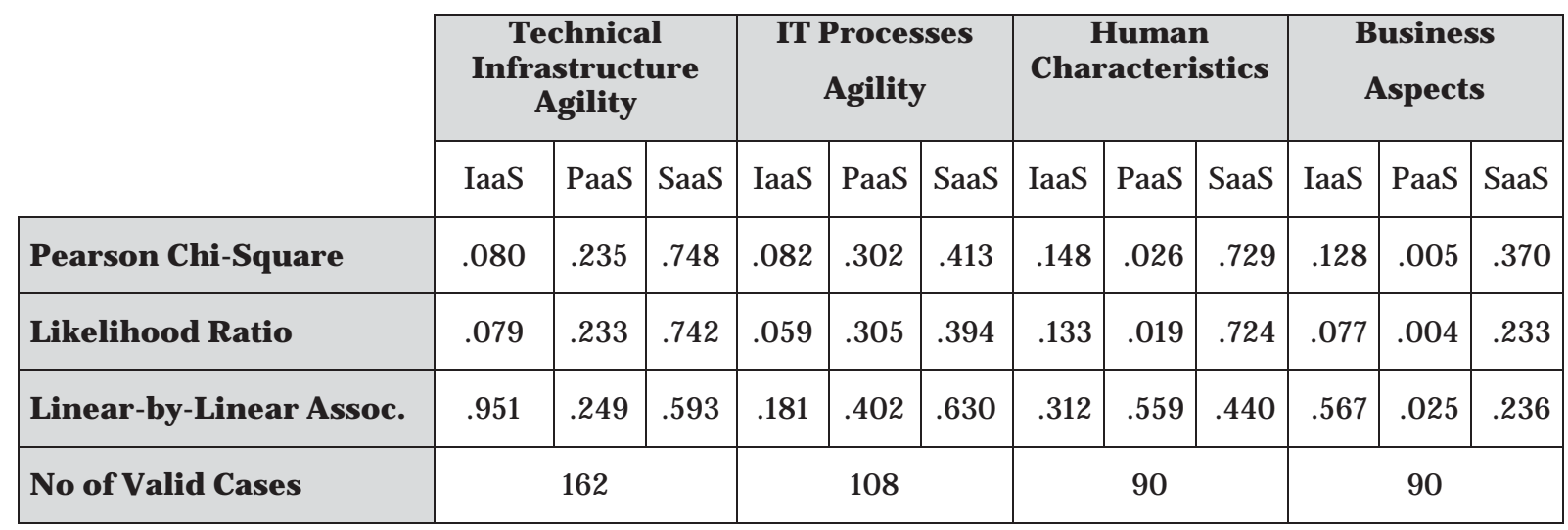

TABLE 6. Chi-Square Tests (Asymp. Sig. (2-sided) ) Technical Infrastructure Agility (TIA), IT Processes Agility (IPA), Human Characteristics (HC), Business Aspects (BA) using different Service Models (Infrastructure-as-a-Service, Platform-as-a-Service, Softwareas-a-Service)

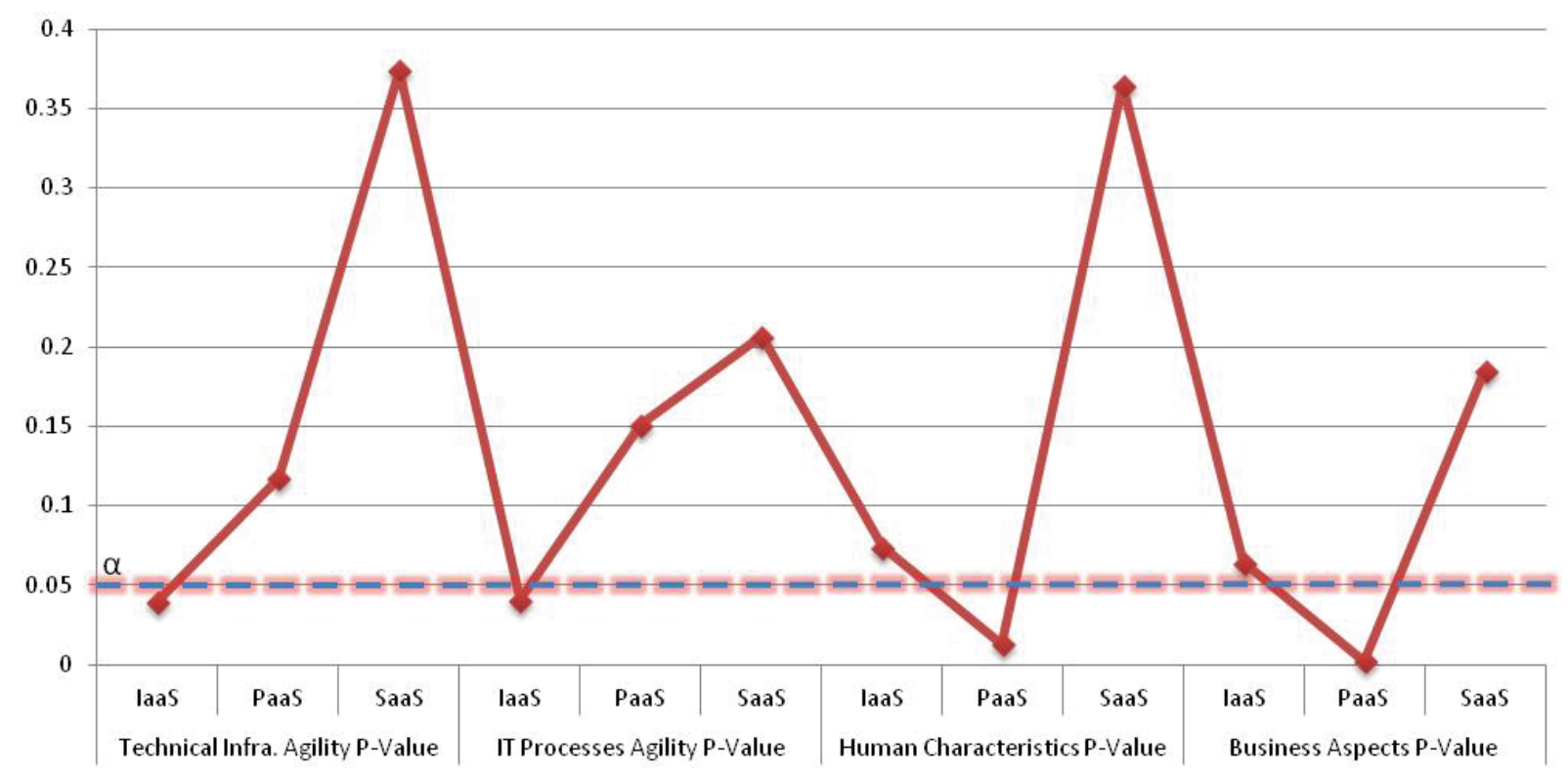

Figure 5. Hypotheses test analysis using Pearson Chi-Square Asymp. Sig. P-Value (1-sided) of the different Service Models compared to a significance level $\alpha=0.05$ (95\% confidence level).

As can be seen in Figure 5, with a level of significance of $\alpha=5 \%$, the one sided P-Value $<\alpha$ for four different associations. Table 7 summarizes the results based on the chi-square tests with the null hypothesis being "there is no association" and the alternative hypothesis being that "an association exists". 


\begin{tabular}{|c|c|c|c|}
\cline { 2 - 4 } \multicolumn{1}{c|}{} & IaaS & PaaS & SaaS \\
\hline $\begin{array}{c}\text { Technical Infrastructure } \\
\text { Agility }\end{array}$ & Reject null & Fail to reject null & Fail to reject null \\
\hline IT Processes Agility & Reject null & Fail to reject null & Fail to reject null \\
\hline Human Characteristics & Fail to reject null & Reject null & Fail to reject null \\
\hline Business Aspects & Fail to reject null & Reject null & Fail to reject null \\
\hline
\end{tabular}

Table 7: Hypotheses testing results for combinations of cloud service models and categories of IS agility with null hypothesis $\mathrm{H}_{0}$ being no association and alternative hypothesis $\mathrm{H}_{\mathrm{A}}$ being association exists.

The following conclusions can be summarized accordingly:

Conclusion 1: There is sufficient evidence to conclude that there is an association between using IaaS as a cloud service model and improving the technical infrastructure agility or the IT Process Agility of the IS. There is no evident association between IaaS and other agility categories.

Conclusion 2: There is sufficient evidence to conclude that there is an association between using PaaS as a cloud service model and improving the Human characteristics or the Business Aspects of the IS. There is no association between PaaS and other agility categories.

Conclusion 3: There is no association between SaaS and any agility category. This conclusion was a quiteinteresting given that SaaS would normally imply less IT staff and fixed running IT cost which would normally imply more business agility. This conclusion opens the door for morefuture research on this topic.

The cloud is about providing services: Infrastructure as a Service (IaaS), Platform as a Service (PaaS), or Software as a Service (SaaS). Another way to look at it: The cloud is about providing a pool of computing resources that all operate together, effectively as a single computer. However as can be noted from the conclusions resulting from the statistical analysis, not all of these services have a direct association with agility as perceived by IT professionals. More specifically, PaaS cloud model gives users the ability to respond to business demands more effectively and helps ensure employees have on demand access to critical business information, customers, partners, and each other, using nearly any device, from virtually anywhere. Therefore, users can give priority to the most critical business tasks first, hence conclusion 2. However, IaaS focuses more on decreasing the management burden of anticipating and building out excess capacity IT infrastructure resulting in less management, maintenance, and deployment time, with the additional benefit of greater scalability to more easily handle peaks in demand; hence, Conclusion 1. Conclusion 3 shows the lack of association between SaaS and any agility category. This conclusion is supported by the fact that SaaS is more perceived as a cost saving option rather than an agility enhancement. In contrast to conventional financial models of software vendors who depend upon up front software license fees to support their P\&Ls, SaaS allows users to pay for only what is utilized during a given period but at the same time results in far less dependency on local IT staff and services which would raise some limitations on agility in general.

A right-tailed t-tests for the difference in numbers of those who see agility improvement, and those who do not, are given in Table 8. 


\begin{tabular}{|l|c|c|c|}
\multicolumn{1}{c|}{ One-Sample Test \& Statistics } \\
\cline { 2 - 4 } \multicolumn{1}{c|}{ Mean } & $\begin{array}{c}\text { Std. } \\
\text { Deviation }\end{array}$ & $\begin{array}{c}\text { Std. Error } \\
\text { Mean }\end{array}$ \\
\hline Mean Technical Infra. Agility & 0.2901 & 0.35982 & 0.08481 \\
\hline Mean IT Processes Agility & 0.3148 & 0.37438 & 0.08824 \\
\hline Mean Human Characteristics & 0.2111 & 0.41429 & 0.09765 \\
\hline Mean Business Aspects & 0.5278 & 0.41911 & 0.09879 \\
\hline
\end{tabular}

\begin{tabular}{|l|c|c|c|c|c|}
\cline { 2 - 6 } \multicolumn{1}{c|}{} & $\mathbf{t}$ & Sig. (2-tailed) & \multicolumn{2}{c|}{$\begin{array}{c}\text { Mean } \\
\text { Difference }\end{array}$} & \multicolumn{2}{c|}{$\begin{array}{c}\text { 95\% Conf. Interval } \\
\text { of the Difference }\end{array}$} \\
\cline { 5 - 7 } & & & Lower & Upper \\
\hline $\begin{array}{l}\text { Mean Technical Infra. Agility } \\
\text { (Test Value=0.14) }\end{array}$ & 1.77 & 0.095 & 0.15012 & -0.0288 & 0.3291 \\
\hline $\begin{array}{l}\text { Mean IT Processes Agility } \\
\text { (Test Value=0.16) }\end{array}$ & 1.754 & 0.097 & 0.15481 & -0.0314 & 0.341 \\
\hline $\begin{array}{l}\text { Mean Human Characteristics } \\
\text { (Test Value=0.04) }\end{array}$ & 1.752 & 0.098 & 0.17111 & -0.0349 & 0.3771 \\
\hline $\begin{array}{l}\text { Mean Business Aspects } \\
\text { (Test Value=0.35) }\end{array}$ & 1.8 & 0.09 & 0.17778 & -0.0306 & 0.3862 \\
\hline
\end{tabular}

TABLE 8. Right-tailed t-Tests for the difference in percentage between those who see agility improvement and those who do not (tests were performed for the various agility dimensions).

As can be seen in Table 8, with a level of significance of $\alpha=5 \%$, the one sided P-Value is less than $\alpha$ for the different test values $(0.14,0.16,0.04$, and 0.35). Figure 6. summarizes the results of t-Tests regarding the consent among population elements pertaining to agility gains achieved.

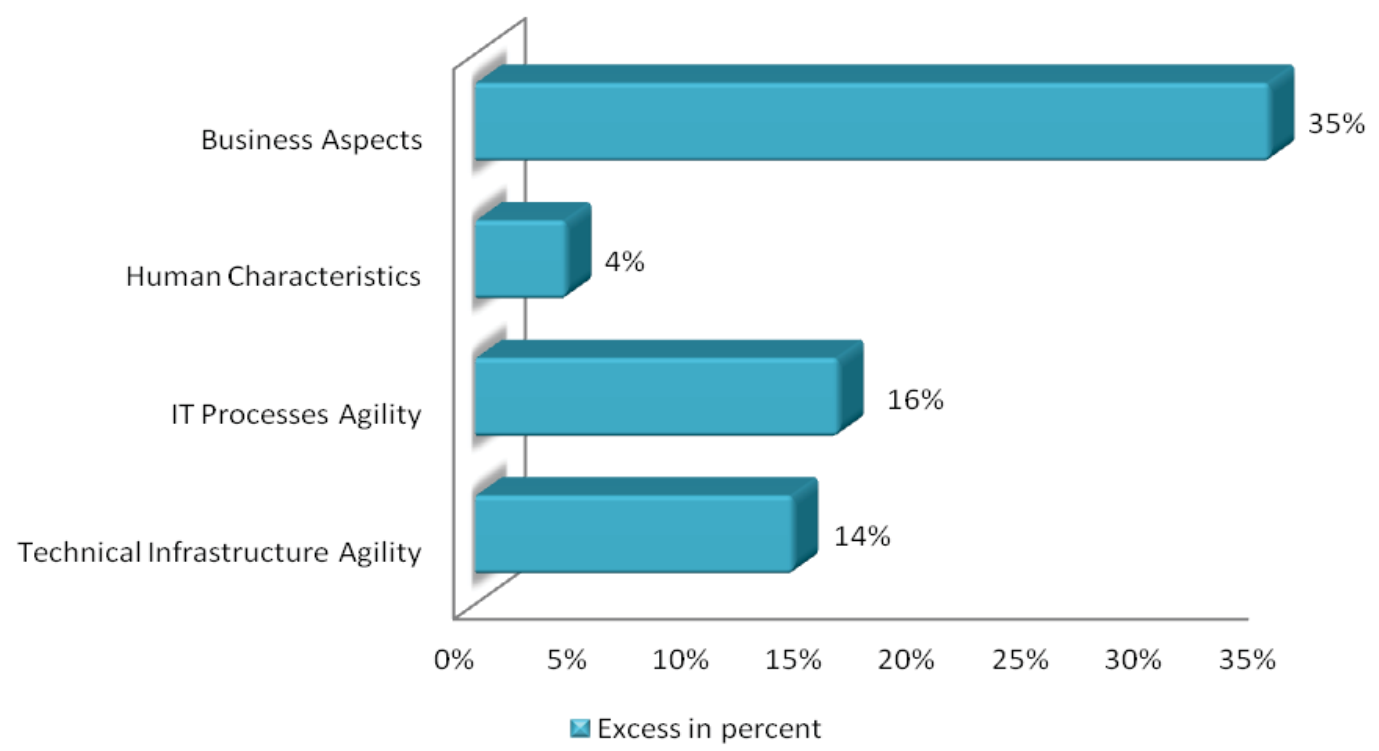

Figure 6. Hypotheses testing results for population elements who see agility improvement exceeding those who see otherwise.

The following conclusion can be summarized:

Conclusion 4: There is sufficient evidence to say that the average number of population elements who seeagility improvement in technical infrastructureagility, IT 
process Agility, Human Characteristics, and Business Aspects exceeds the number of those who see otherwise by more than $14 \%, 16 \%, 4 \%$ and $35 \%$ respectively.

From conclusion 4, it is evident that our initial findings from Figure 3 are further confirmed with regards to the high percentage of responses to business aspects agility improvements. More specifically, this percentage difference is a result of cloud computing improvements in: user confidence to counter unexpected changes, efficiency and effectiveness in seizing emerging opportunities, and alignment of IT strategies with business strategies.

Also, an evident observation from Figure 6 is regarding the high percentage of acceptance on agility improvement with regards to process agility. More specifically, this percentage difference is a result of positive responses to cloud computing models implications. These implications include: decreasing time and effort for support and maintenance, simplifying new branch integration, decreasing the effort to evaluate and prioritize proposed changes, easier capacity planning and performance information gathering, and simplified service management.

\section{Discussion and Conclusion}

The research question of this study was about measuring the impact of cloud computing on IS agility. To evaluate how cloud computing changes IS agility, it started by conducting a literature review and then compiled four groups of attributes in a proposed testing framework to be considered when looking at IS agility. A survey was built based on these attributes and was distributed to senior IT executives and professionals from companies who have deployed some sort of cloud computing. These companies were selected from different industries to make the sample more representative, participants responses were collected and statistically analyzed in order to find any associations between using cloud computing and improving agility.

Based on results of the research, we concluded that some cloud computing service models improve specific agility dimensions, for example, IaaS improves technical infrastructure agility and PaaS improves Human Characteristics while SaaS does not associate with any category. Wealso concluded that agility improvements in the business aspects were the dominant agility category in the IT industry. In general, it seems that cloud computing still needs a lot of improvement in order to convince businesses on the agility aspects it can provide. More precisely, additional work needs to be done on SaaS association with different categories of agility among others.

\section{References}

Buyya, R., Yeo, C., Venugopal, S., Broberg, J, Brandic, I., (2009). Cloud computing and emerging IT platforms: vision, hype, and reality for delivering computing as the 5th utility, Future Generation Computer Systems 25 (6) 599- 616.

Byrd, T, and Turner, D, (2000). "Measuring the Flexibility of Information Technology Infrastructure: Exploratory Analysis of a Construct," J. Manage. Inf. Syst., vol. 17, pp. 167-208.

Carroll, M., van der Merwe, A., and Kotze, P. (2011). Secure cloud computing: Benefits, risks and controls, pp. 1-9.

Ciurana, E (2009). Developing with Google App Engine, Apress, Berkeley, CA, USA.

Cusumano, M (2010). Cloud computing and SaaS as new computing platforms, Communications of the ACM 53 (4) 27-29.

Dove, R. (2001). Response Ability: the Language, Structure and Culture of Agile Enterprise, Wiley Publishers, ISBN: 978-0-471-35018-7. 
Garg, S., Versteeg, S., and Buyya, R., (2013). "A framework for ranking of cloud computing services," Future Generation Computer Systems, vol. 29, p. 1-12.

Imache, R, Izza, S and Ahmed-Nacer, M, (2012). "An enterprise information system agility assessment model," Computer Science and Information Systems, vol. 9, pp. 107-133.

Izza, S, Imache, R, Vincent, L, and Lounis, Y (2008). An Approach for the Evaluation of the Agility in the Context of Enterprise Interoperability, ed: Springer, pp. 3-14.

J orfi, S., Md Nor, K, and Najjar, L (2011). "The Relationships Between IT Flexibility, ITBusiness Strategic Alignment, and IT Capability," International J ournal of Managing Information Technology, vol. 3, pp. 16-31.

Li, Z., O'Brien, L., Zhang, H., and Cai, R. (2013). On a Catalogue of Metrics for Evaluating Commercial Cloud Services, 1-10.

Maurer, C (2010). "Measuring Information Systems Agility: Construct Definition and Scale Development," SAIS 2010 Proceedings.

Overby, E., Bharadwaj, A. and Sambamurthy, V. (2006). "Enterprise agility and the enabling role of information technology," European J ournal of Information Systems, vol. 15, pp. 120-131.

Perdue, Jeff, Siegel, Jane, (2011). Cloud-Services-Measurement-Initiative-Consortium". CSMIC Framework, v1.0, Carnegie Mellon University Silicon Valley.

Pessi, K., Magoulas, T. and Hugoson, M. (2009). "Architectural principles for alignment within the context of agile enterprises," in Proceedings of the 3rd European Conference on Information Management and Evaluation, Sweden.

Rimienė, K. (2011). "Supply chain agility concept evolution (1990-2010)," Economics and Management, pp. 892-899.

Yang, H., Huff, S., and Tate, M. (2013). "Managing the Cloud for Information Systems Agility," in Cloud Computing Service and Deployment Models: Layers and Management, ed: IGI Global, pp. 70-93.

Copyright: (C) 2015 Sawas \&Watfa. This is an open-access article distributed under the terms of the Creative Commons Attribution-NonCommercial 3.0 Australia License, which permits non-commercial use, distribution, and reproduction in any medium, provided the original author and AJ IS are credited.

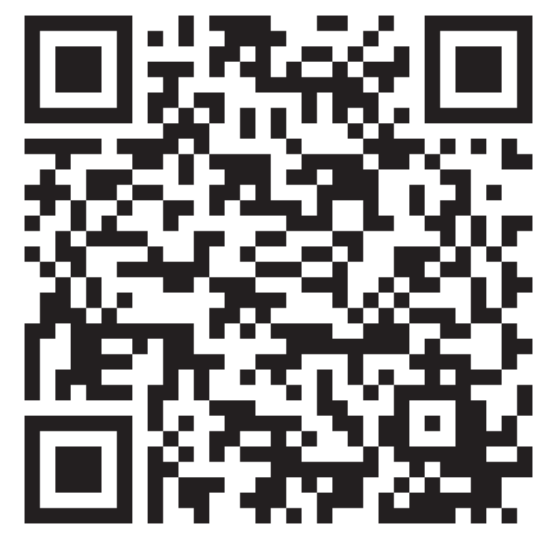

